\title{
MiR-9, miR-21, and miR-155 as potential biomarkers for HPV positive and negative cervical cancer
}

Sunyoung Park ${ }^{1 \dagger}$, Kiyoon Eom ${ }^{1 \dagger}$, Jungho Kim², Hyeeun Bang ${ }^{2}$, Hye-young Wang², Sungwoo Ahn', Geehyuk Kim', Hyoungsoon Jang ${ }^{1}$, Sunghyun $\mathrm{Kim}^{3}$, Dongsup Lee ${ }^{4}$, Kwang Hwa Park ${ }^{5^{*}}$ and Hyeyoung Lee ${ }^{1^{*}}$

\begin{abstract}
Background: Cervical cancer is the second leading cause of death among female patients with cancer in the world. High risk human papillomavirus has causal roles in cervical cancer initiation and progression by deregulating several cellular processes. However, HPV infection is not sufficient for cervical carcinoma development. Therefore, other genetic and epigenetic factors may be involved in this complex disease, and the identification of which may lead to better diagnosis and treatment. Our aim was to analyze the expression of microRNAs in cervical cancer cases positive or negative for HPV E6/E7 mRNA, and to assess their diagnostic usefulness and relevance.

Methods: The expression of three different microRNAs (miR-9, miR-21, and miR-155) in 52 formalin-fixed paraffin-embedded (FFPE) primary cervical cancer tissue samples and 50 FFPE normal cervical tissue samples were evaluated.

Results: MiR-9, miR-21, and miR-155 were significantly overexpressed in cervical cancer tissues compared to normal tissues $(P<0.001)$. MiR-21 and miR-155 expression combined with the HPV E6/E7 mRNA assay in HPV E6/E7 negative cervical cancer showed increased AUC of 0.7267 and 0.7000 , respectively $(P=0.01, P=0.04)$, demonstrating their potential as diagnostic tools. Moreover, miR-21 and miR-155 were predictors showing a 7 fold and 10.3 fold higher risk for HPV E6/E7 negative patients with cervical cancer $(P=0.024$ and $P=0.017$, respectively) while miR-155 was a predictor showing a 27.9 fold higher risk for HPV E6/E7 positive patients with cervical cancer $(P<0.0001)$.

Conclusions: There is a strong demand for additional, alternative molecular biomarkers for diagnosis and management of precancer patients. MiR-21 and miR-155 may be helpful in the prediction of both HPV positive and HPV negative cases of cervical cancer.
\end{abstract}

Keywords: Cervical cancer, microRNA, HPV E6/E7, RT-qPCR, Molecular diagnosis

\section{Background}

Cervical cancer is the third most common malignancy in women worldwide [1]. High risk human papillomavirus (HR-HPV) infection is recognized as the most important risk factor in cervical cancer. Persistent over-expression of

\footnotetext{
*Correspondence: abba@yonsei.ac.kr; hyelee@yonsei.ac.kr

${ }^{\dagger}$ Equal contributors

${ }^{5}$ Department of Pathology, Wonju College of Medicine, Yonsei University Wonju College of Medicine, 20 Ilsan-ro, Wonju-si, Gangwon-do 26426, Republic of Korea

'Department of Biomedical Laboratory Science, College of Health Sciences, Yonsei University, Wonju-si, Gangwon-do 26493, Republic of Korea Full list of author information is available at the end of the article
}

the E6 and E7 oncogenes encoded in the HPV genome have a critical role in the development of cervical cancer by causing genetic and epigenetic instability [2]. HPV E6 leads to the degradation of $\mathrm{p} 53$, which is a critical tumor suppressor that regulates abrogation of cell growth arrest. Furthermore, HPV E7 binds and deactivates another important tumor suppressor, the retinoblastoma protein $(\mathrm{pRb})$, thereby interfering with cell cycle regulation [3-6].

Recently, several studies reported the development of cervical cancers that are HPV negative despite increased sensitivity of HR-HPV detection methods. Through meta-analyses of HPV detection methods, both Tjalma, 
et al. and Giorgi, et al. found that 4.2 to $8.2 \%$ of cases were HPV negative in 574 invasive cervical cancers and 3162 invasive cervical cancers [7, 8]. A large international retrospective cross-sectional study including 10,575 cases with invasive cervical cancer found that 15\% (1598 cases) were negative for HPV DNA [9]. Similarly, our previous study also found that $15 \%$ of patients with cervical cancer (100 cases) were HPV negative [10].

Epigenetic instability is affected by microRNAs (miRNA or miR-). MiRNAs are 19 to 25 nucleotides (nt) in length, and have a role in transcriptional and epigenetic regulation through binding the 3'-UTR of the target-mRNA $[11,12]$. It is now widely known that miRNA dysregulation is associated with a wide variety of human malignancies, such as breast cancer, lung cancer, colon cancer, and gastric cancer [13-16].

Many miRNAs studies have tried to confirm the utility of each miRNAs in cervical cancers with different methods. Lui et al. used miRNA direct sequencing analysis with six human cervical carcinoma cell lines and frozen cervical tumor tissues [17]. Lee et al. had miRNA expression profiling with 157 panel analyses with frozen cervical tumor tissues [18]. Gocze et al. utilized quantitative real time polymerase chain reaction (RT-qPCR) of eight miRNAs (miR-21, miR-27a, miR-34a, miR-146a, miR-155, miR-196a, miR-203, miR-221) individually [19].

Among these several miRNAs, three miRNAs (miR-9, miR-21, and miR-155) having their revealed targets that might be related to cancer were selected. Ma et al. showed miR-9 increased cell motility and invasiveness by targeting Cadherin $1(\mathrm{CDH} 1)$ and lead to cancer metastasis [20]. Asangani et al. and Bumrungthai et al. showed miR-21 promoted invasion and cell proliferation targeting programmed cell death 4(PDCD4) [21, 22]. MiR-155 expression promotes the proliferation targeting liver kinase B1 (LKB1) [23, 24].

Although the roles of these three miRNAs (miR-9, miR-21, and miR-155) have been studied in cervical cancer, their potential diagnostic or prognostic value in a clinical setting has not been examined. In addition, it is not known whether there is an association between these three miRNAs and HR-HPV infection status in clinical tissue specimens. Therefore, the purpose of this study was to investigate miR-9, miR-21, and miR-155 expression levels in cervical cancer and normal tissue samples, and determine their possible relation to HR-HPV E6/E7 oncogene expression.

\section{Methods}

\section{Clinical samples}

A total of 52 FFPE cervical cancer tissue samples and 50 FFPE normal cervical tissue samples were used from the Department of Pathology, Yonsei University Wonju
Severance Christian Hospital, Wonju, Republic of Korea, between January 2010 and December 2014 (Table 1). Institutional Ethics Committee at Yonsei University Wonju College of Medicine approved the study protocol (approval no. YWMR-12-4-010) and all subjects provided written informed consent. Cases with tissue biopsies available were reviewed by two pathologists. The 52 cervical cancer samples consisted of tissue samples from 50 squamous cell carcinomas and 2 adenocarcinomas.

Deparaffinization of FFPE tissues and total RNA extraction Three to four $10-\mu \mathrm{m}$ thick sections of FFPE cervical tissue were used for total RNA extraction. To remove paraffin from FFPE tissue, $160 \mu \mathrm{L}$ of Deparaffinization solution (Qiagen, Hilden, Germany) was added and vortexed, followed by incubation for $3 \mathrm{~min}$ at $56{ }^{\circ} \mathrm{C}$. RNA extraction was performed using the Qiagen RNeasy FFPE kit (Qiagen, Hilden, Germany) according to the manufacturer's protocol. Total RNA purity and concentration were determined by measuring the ratio of the absorbance at 260 and $280 \mathrm{~nm}$ using an Infinite 200 spectrophotometer (Tecan, Salzburg, Austria). All preparation and handling procedures were conducted under RNase-free conditions. Isolated total RNA was stored at $-70{ }^{\circ} \mathrm{C}$ until used.

\section{cDNA synthesis}

Complementary DNA (cDNA) was synthesized using a TaqMan microRNA Reverse Transcriptase kit (Applied Biosystems by Life Technologies, Foster City, CA, USA) according to manufacturer's instructions. Briefly, 5 to $10 \mathrm{ng}$ of total RNA was used for cDNA synthesis. The reverse transcriptase (RT) reaction mixture contained $0.15 \mu \mathrm{L}$ of $100 \mathrm{mM}$ dNTP mix (100 mM each dATP, dGTP, dCTP, and dTTP at a neutral pH), $1 \mu \mathrm{L}$ of $50 \mathrm{U} / \mu \mathrm{L}$ reverse transcriptase, $1.5 \mu \mathrm{L}$ of $10 \times$ reverse transcriptase buffer, $0.19 \mu \mathrm{L}$ of $20 \mathrm{U} / \mu \mathrm{L}$ RNase inhibitor, and adjusted the total reaction volume to $15 \mu \mathrm{L}$ with nuclease free

Table 1 Sample information in cervical cancer and normal

\begin{tabular}{lll}
\hline Variables & Cancer, $\mathrm{n}(\%)$ & Normal, $\mathrm{n}(\%)$ \\
\hline Age & & \\
$\quad<50$ years & $18(34.6)$ & $31(62.0)$ \\
$\geq 50$ years & $34(65.4)$ & $19(38.0)$ \\
Histology & & \\
SCC & $50(96.2)$ & \\
ADC & $2(3.8)$ & \\
HPV E6/E7 mRNA expression & & $0(0)$ \\
Positive & $37(71.2)$ & $50(100)$ \\
Negative & $15(28.8)$ & $50(100)$ \\
Total & $52(100)$ &
\end{tabular}

SCC Squamous cell carcinoma, $A D C$ Adenocarcinoma 
water. The cDNA synthesis reaction was performed as follows: $16{ }^{\circ} \mathrm{C}$ for $30 \mathrm{~min}$ followed by $42{ }^{\circ} \mathrm{C}$ for $30 \mathrm{~min}$, and $85{ }^{\circ} \mathrm{C}$ for $5 \mathrm{~min}$.

\section{MiRNA analysis using RT-qPCR}

MiRNA expression was quantified by determining the cycle threshold $\left(\mathrm{C}_{\mathrm{T}}\right)$ which is the number of PCR cycles required for the fluorescence to exceed a value significantly higher than the background fluorescence, using the TaqMan small RNA assay (Applied Biosystems by Life Technologies) with miRNA specific primers according to manufacturer's instructions. Briefly, $1.4 \mu \mathrm{L}$ of cDNA was added to $10 \mu \mathrm{L}$ of probe qPCR mix and $7.6 \mu \mathrm{L}$ of nuclease free water. The following TaqMan small RNA assay (Applied Biosystems) primers were used: hsa-miR-9-5p, hsa-miR-21-5p, hsa-miR155-5p, and RNU6B. All analyzed miRNAs are of human (Homo sapiens) origin and therefore, the prefix "hsa" is omitted throughout the text. RT-qPCR reactions were performed using a CFX96 Real-Time PCR System Detector (Bio-Rad, Hercules, CA, USA). Samples were run in duplicate for each experiment. Data were analyzed using the comparative Ct $\left(2-\Delta \Delta C_{T}\right)$ method using the small nuclear RNA, RNU6B, as an endogenous control. To monitor reagent contamination, negative controls were included for each primer pair. PCR cycling conditions were as follows: $95{ }^{\circ} \mathrm{C}$ for 3 min 40 cycles of $95{ }^{\circ} \mathrm{C}$ for $15 \mathrm{~s}$ and $60{ }^{\circ} \mathrm{C}$ for $60 \mathrm{~s}$.

\section{HPV E6/E7 mRNA analysis using RT-qPCR}

To detect HPV E6/E7 mRNA in FFPE cervical tissues, multiplex RT-qPCR was performed using the TaqMan assay with the OPTIMYGENE HPV E6/E7 mRNA RTqDx assay kit (Optipharm, Osong, Republic of Korea). PCR primers and the corresponding TaqMan probes were designed for three different sets of HPV regions, with each set of probes targeting their conserved sequence (FAM: HPV genotypes 16, 31, 33, 35, 52, and 58; CY5: HPV genotypes 18, 39, 45, 51, 59, and 68; and HEX: HPV genotypes 53, 56, 66, and 69).

RT-qPCR reactions consisted of $10 \mu \mathrm{L}$ of $2 \times$ Thunderbird probe qPCR mix (Toyobo, Osaka, Japan), $5 \mu \mathrm{L}$ of primers and TaqMan probe mixture, $2 \mu \mathrm{L}$ of template cDNA, and distilled water for a final reaction volume of $20 \mu \mathrm{L}$. The multiplex RT-qPCR assay detected the HPV E6 and E7 genes simultaneously in a single tube by incorporating two targets (E6 and E7) using specific TaqMan probes, which were labeled with different fluorophores (FAM, HEX, and $\mathrm{Cy} 5$ ). Positive and negative controls were included throughout the procedure. PCR cycling conditions were as follows: $95^{\circ} \mathrm{C}$ for $3 \mathrm{~min} 45$ cycles of $95^{\circ} \mathrm{C}$ for $20 \mathrm{~s}$ and $60{ }^{\circ} \mathrm{C}$ for $40 \mathrm{~s}$. To avoid false negatives because of mRNA degradation, glyceraldehyde-3-phosphate dehydrogenase (GAPDH) was used as an endogenous control.

\section{Statistical analysis}

Statistical analysis was performed using GraphPad Prism software version 5.02 (GraphPad, La Jolla, CA, USA) and MedCalc 9.0 software (MedCalc Software Inc., Mariakerke, Belgium). Student's t-test and Mann Whitney $U$ test were used to determine statistical significance between cervical cancer and normal cervical tissue samples as well as investigate miRNA expression in patients according to HPV infection status. Receiver operating characteristic (ROC) curves were generated to assess diagnostic accuracy of each miRNA, and the area under the ROC curve (AUC) was calculated to measure discriminatory capacity. The best sensitivity/specificity pair was selected based on the maximum likelihood ratio. Univariate and multivariate logistic regression by odds ratio (OR) and 95\% confidential interval ( $95 \% \mathrm{CI}$ ) were performed to assess predictors for cervical cancer diagnosis using the XLSTAT software (Addinsoft, New York, USA). All statistical tests were two-sided, and a $P$ value $\leq 0.05$ was considered statistically significant.

\section{Results}

\section{HPV E6/E7 mRNA expression in cervical cancer tissues}

Prior to investigating miRNA expression levels, we first examined HPV E6/E7 mRNA expression in 52 FFPE cervical cancer tissue samples and 50 FFPE normal control samples. Fifteen (28.8\%) of the 52 FFPE cervical cancer tissue samples were negative for HR-HPV E6/E7 expression (termed HR-HPV E6/E7-negative), while 37 (71.2\%) samples were positive (termed HR-HPV E6/E7-positive). We found that all 50 FFPE normal cervical control samples were negative for HPV E6/E7 mRNA expression (Table 1).

\section{MiRNA expression levels in cervical cancer and normal tissues}

Expression levels of miR-9, miR-21, and miR-155 were investigated in our 52 FFPE cervical cancer tissue samples and 50 FFPE normal cervical tissue controls. All three miRNAs were significantly up regulated in FFPE cervical cancer tissues compared to FFPE normal cervical tissues $(P<0.0001)$ (Fig. 1a-c). The AUC was 0.7565 [95\% confidence interval $(\mathrm{CI})=0.6624-0.8507$ ] in miR-9, 0.8325 (95\% CI $=0.7530-0.9120)$ in miR-21, and $0.8492(95 \% \mathrm{CI}=0.7736-0.9249)$ in miR-155, all of which indicate these miRNAs may be used as potential biomarkers for cervical cancer (Fig. 1d-f).

\section{Diagnostic value of miR-9, miR-21, and miR-155 miRNAs}

To assess the potential diagnostic value of these three miRNAs, the performance characteristics sensitivity, specificity, positive predictive value, and negative 


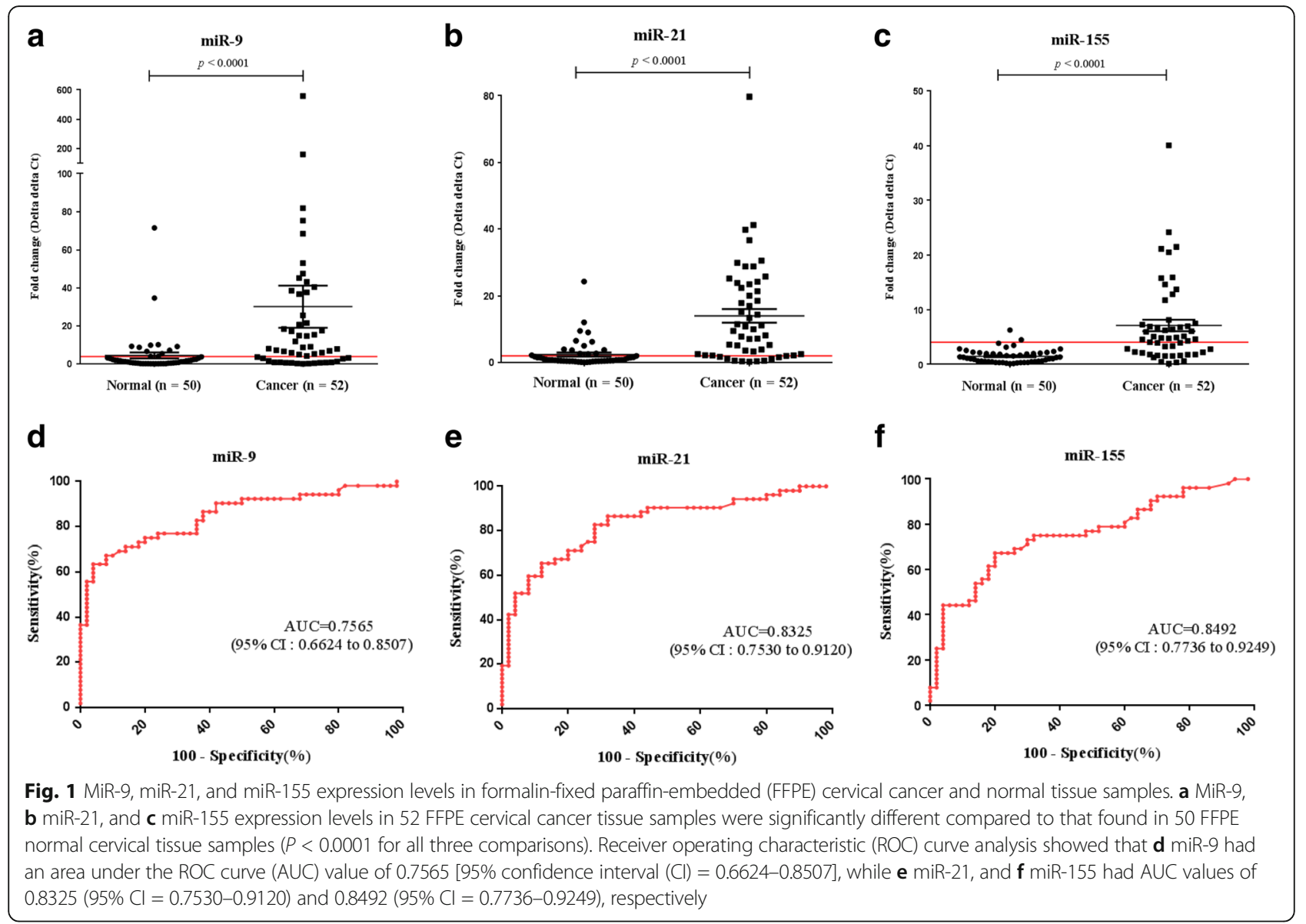

predictive value were determined and evaluated. The cut-off values of miR-9, miR-21, and miR-155 as determined using the likelihood ratio, were 4.035, 1.975, and 3.880 respectively, for optimal sensitivity and specificity. The sensitivity of miR-9, miR-21, and miR-155 was $67.3 \%(95 \% \mathrm{CI}=52.9-79.7), 82.7 \%(95 \% \mathrm{CI}=69.7-$ 91.8), and $65.4 \%$ (95\% CI $=50.9-78.0)$ respectively, while the specificity was $80.0 \%(95 \% \mathrm{CI}=66.3-90.0)$ for $\mathrm{miR}$ 9, $72.0 \%$ (95\% CI $=57.5-83.8$ ) for miR-21, and $96.0 \%$ (95\% CI $=86.3-99.5)$ for miR-155. Positive predictive values (PPVs) of miR-9, miR-21, and miR-155 were $77.8 \%, 75.4 \%$, and $94.3 \%$ respectively, while the respective negative predictive values (NPVs) were $70.2 \%, 80.0 \%$, and $71.6 \%$ (Table 2).

\section{MiR-9, miR-21, and miR-155 in HPV E6/E7-positive and -negative cervical cancer}

To investigate the expression of miR-9, miR-21, and miR-155 with cervical cancer cases that were HPV E6/ E7 mRNA-positive or -negative for HPV E6/E7 mRNA, expression levels of the three miRNAs were analyzed in three groups: HPV E6/E7-positive cancer samples, HPV E6/E7-negative cancer samples, and normal samples. We found that all three miRNAs were significantly up regulated in HR-HPV E6/E7-positive cancer tissue samples compared to normal tissue samples $(P<0.0001)$, while miR-21 and miR-155 were up regulated in HPV E6/E7negative cancer tissue samples compared to normal controls $(P=0.0079$ and $P=0.0384$, respectively). We

Table 2 Clinical cut-off values, sensitivity, and specificity of miRNAs

\begin{tabular}{lllllll}
\hline & Cut-off value & Sensitivity, \% (95\% Cl) & Specificity, \% (95\% Cl) & PPV, \% (95\% Cl) & NPV, \% (95\% Cl) & Likelihood ratio \\
\hline miR-9 & $>4.035$ & $67.3(52.9-79.7)$ & $80.0(66.3-90.0)$ & $77.8(62.9-88.8)$ & $70.2(56.6-81.6)$ & 3.4 \\
miR-21 & $>1.975$ & $82.7(69.7-91.8)$ & $72.0(57.5-83.8)$ & $75.4(62.2-85.9)$ & $80.0(65.4-90.4)$ & 3.0 \\
miR-155 & $>3.880$ & $65.4(50.9-78.0)$ & $96.0(86.3-99.5)$ & $94.3(80.8-90.6)$ & $71.6(59.3-82.0)$ & 15.9 \\
\hline
\end{tabular}

95\% Cl 95\% confidence interval, $P P V$ positive predictive value, NPV negative predictive value 
found no significant difference in miR-9 expression levels between HR-HPV E6/E7-negative cancer samples and normal cervical samples (Fig. 2).

\section{Diagnostic value of miR-9, miR-21, and miR-155 miRNAs in conjunction with the HPV E6/E7 mRNA assay}

The effectiveness of each three miRNA combined with HPV E6/E7 mRNA assay was investigated by analysis of AUC. In all cases of cervical cancer, the value of AUC was 0.8558 (95\% CI $0.7773-0.9343$ ), 0.8135 (95\% CI $0.7257-$ 0.9013), 0.8215 (95\% CI 0.7349-0.9082), 0.8935 (95\% CI 0.8243-0.9626) in HPV E6/E7, HPV E6/E7 + miR-9, HPV E6/E7 + miR-21, and HPV E6/E7 + miR-155, respectively. Especially, in HPV negative cervical cancer, miR-21 and miR-155 in conjunction with the HPV E6/E7 mRNA was shown increased AUC value of 0.7267 (95\% CI $0.5776-$ $0.8757)$ and 0.7000 (95\% CI $0.5152-0.8646)$ respectively, compared to HPV E6/E7 assay (Table 3).

\section{MiRNA predictors for diagnosing cervical cancer in HPV E6/E7-negative cases}

We analyzed the following risk predictors of cervical cancer: age, HPV E6/E7 mRNA-expressing status, and miR-9, miR-21, and miR-155 expression. We found that the highest risk factor was HPV E6/E7 mRNA expression $(\mathrm{OR}=244.4,95 \% \mathrm{CI}=13.6-4376.4)$ followed by expression of miR-155 (OR $=41.7,95 \% \mathrm{CI}=9.1-191.2)$, miR-21 $(\mathrm{OR}=12.3,95 \% \mathrm{CI}=4.8-31.7)$, and miR-9 $(\mathrm{OR}=8.2$, 95\% $\mathrm{CI}=3.3-20.3)$. Ages below 60 years were not a significant risk factor but being over the age of 60 years did confer a higher risk to cervical cancer (Table 4).
Table 3 Diagnostic values of miRNAs in conjunction with HPV E6/E7 for cervical cancer

\begin{tabular}{llll}
\hline & AUC $^{\mathrm{a}}$ & $95 \% \mathrm{Cl}$ & $P$-value \\
\hline All cases & & & \\
HPV E6/E7 & 0.8558 & $0.7773-0.9343$ & $<0.0001$ \\
HPV E6/E7 + miR-9 & 0.8135 & $0.7257-0.9013$ & $<0.0001$ \\
HPV E6/E7 + miR-21 & 0.8215 & $0.7349-0.9082$ & $<0.0001$ \\
HPV E6/E7 + miR-155 & 0.8935 & $0.8243-0.9626$ & $<0.0001$ \\
HPV negative cases & & & \\
HPV E6/E7 & 0.5000 & $0.3321-0.6679$ & 1.00 \\
HPV E6/E7 + miR-9 & 0.6000 & $0.4284-0.7716$ & 0.24 \\
HPV E6/E7 + miR-21 & 0.7267 & $0.5776-0.8757$ & 0.01 \\
HPV E6/E7 + miR-155 & 0.7000 & $0.5152-0.8648$ & 0.04 \\
\hline
\end{tabular}

${ }^{\mathrm{a}} \mathrm{AUC}$ an area under the ROC curve

To investigate the predictive power for diagnosing cervical cancer in HPV E6/E7 mRNA negative cases, the odds ratio of the miRNAs was determined based on HPV E6/E7 mRNA expression using multivariate analysis. We found that miR-21 and miR-155 in HPV E6/ E7-negative cervical cancer patients conferred a 7.0 $(95 \% \mathrm{CI}=1.3-37.6)$ and $10.3(95 \% \mathrm{CI}=1.5-70.7)$ fold risk to cervical cancer, respectively (Table 5 ).

\section{Discussion}

HPV DNA detection for cervical cancer screening is widely used as an early diagnostic guideline to prevent the progression of cervical cancer. Nevertheless, there is an ongoing need for studies investigating the molecular mechanisms related to cervical cancer carcinogenesis
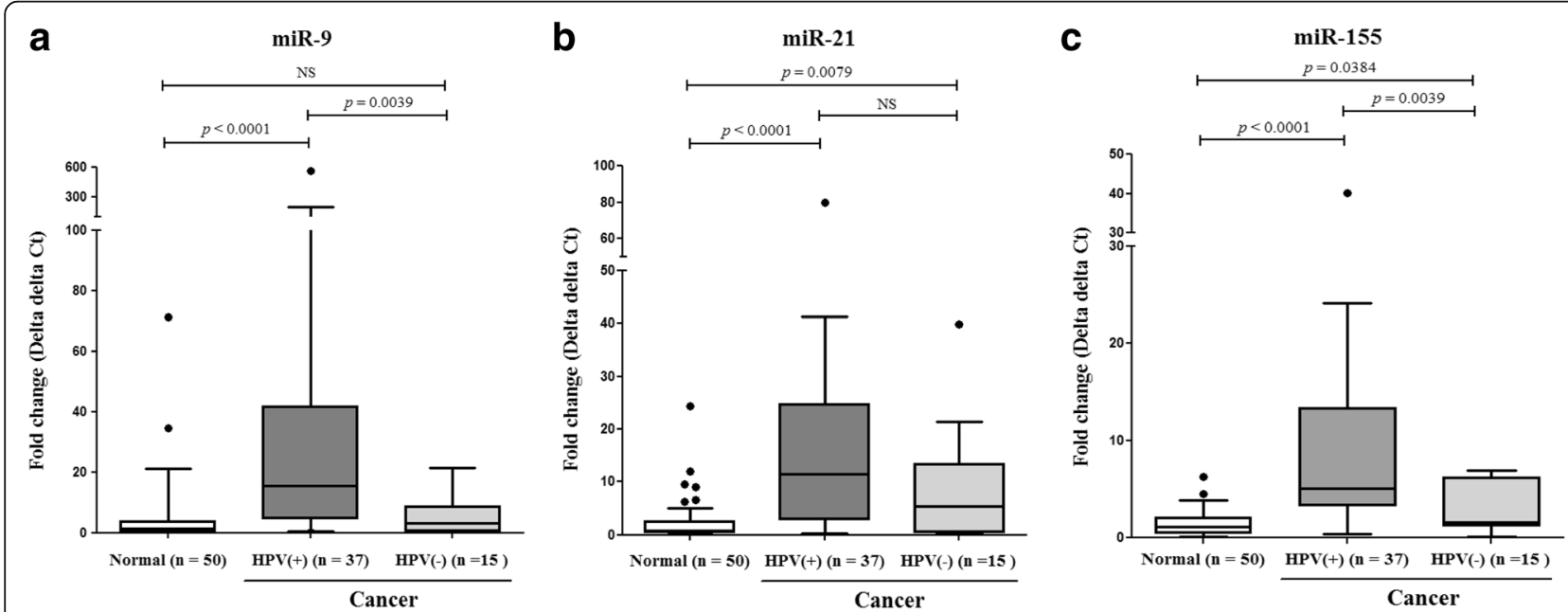

Fig. 2 Box and whisker plots of comparisons between three miRNA expression levels in normal cervical tissues and cancer tissues with (+) or without (-) HPV E6/E7 mRNA expression. a MiR-9, b miR-21, and c miR-155 expression levels in high risk human papillomavirus (HR-HPV) E6/E7-positive cervical cancer tissues were significantly up regulated compared to that found in normal cervical tissue samples $(P<0.0001$ for all three comparisons). MiR-21 and miR-155 expression levels in HR-HPV E6/E7-negative cervical cancer tissues were significantly up regulated compared to that found in normal cervical tissue samples ( $P=0.0079$ and $P=0.00384$, respectively). NS, not significant 
Table 4 The diagnostic utility of predictors for cervical cancer (univariate analysis)

\begin{tabular}{|c|c|c|c|}
\hline & OR & $95 \% \mathrm{Cl}$ & $P$ value \\
\hline \multicolumn{4}{|l|}{ Ages } \\
\hline$<30$ years & 1 & & \\
\hline $31-40$ years & 1.4 & $0.4-5.1$ & 0.580 \\
\hline $41-50$ years & 1.7 & $0.4-6.5$ & 0.442 \\
\hline $51-60$ years & 3.5 & $0.8-16.4$ & 0.109 \\
\hline$>60$ years & 35.2 & $3.6-344.2$ & 0.002 \\
\hline \multicolumn{4}{|l|}{ HPV E6/E7 } \\
\hline negative & 1 & & \\
\hline positive & 244.4 & $13.6-4376.4$ & $<0.0001$ \\
\hline \multicolumn{4}{|l|}{ miR-9 } \\
\hline negative & 1 & & \\
\hline positive & 8.2 & $3.3-20.3$ & $<0.0001$ \\
\hline \multicolumn{4}{|l|}{ miR-21 } \\
\hline negative & 1.0 & & \\
\hline positive & 12.3 & $4.8-31.7$ & $<0.0001$ \\
\hline \multicolumn{4}{|l|}{ miR-155 } \\
\hline negative & 1.0 & & \\
\hline positive & 41.7 & $9.1-191.2$ & $<0.0001$ \\
\hline
\end{tabular}

because most high-risk HPV infections that present without any symptoms go away within one to two years, and there have been reports of several HPV negative cases of cervical cancer $[7-9,25]$. In our previous study, we found that 15 out of 100 FFPE cervical cancer tissue samples were HPV negative using an E6/E7 mRNA assay as well as testing for the HPV L1 genotype (data not shown).

Several oncogenic miRNAs are associated with cervical cancer tumorigenesis [17-23]. However, the results from those studies were not comprehensively evaluated using clinical specimens, and those studies have not tested for an association between miRNA expression levels and HR-HPV E6/E7 mRNA expression in clinical specimens.

Table 5 MiRNA predictors of cervical cancer according to HPV E6/E7 mRNA expression status in patients (multivariate analysis)

\begin{tabular}{cccc}
\hline & OR & $95 \% \mathrm{Cl}$ & $P$ value \\
\hline HPV positive & & & \\
miR-9 & 3.3 & $0.6-18.7$ & 0.173 \\
miR-21 & 1.8 & $0.3-11.1$ & 0.515 \\
miR-155 & 27.9 & $5.0-155.7$ & $<0.0001$ \\
HPV negative & & & \\
miR-9 & 0.4 & $0.1-2.6$ & 0.341 \\
miR-21 & 7.0 & $1.3-37.6$ & 0.024 \\
miR-155 & 10.3 & $1.5-70.7$ & 0.017 \\
\hline
\end{tabular}

OR Odds ratio, $95 \% \mathrm{Cl} 95 \%$ confidential interval
The aim of this study was to explore the potential clinical relevance of miR-9, miR-21, and miR-155 by investigating their expression levels in 52 FFPE cervical cancer tissue samples and in 50 FFPE normal cervical tissue samples. Evidence of association between these three miRNAs and HR-HPV E6/E7 mRNA expression was also investigated.

All three miRNAs (miR-9, miR-21, and miR-155) showed significantly higher expression in cervical cancer tissues compared to that found in normal cervical tissues $(P<0.0001)$ (Fig. 1). This finding supports the possibility that these three miRNAs may be implicated in cervical cancer development in clinical samples. Although four previous studies using cervical cancer cell lines and clinical samples found that miR-21, miR-155, and miR-9 were up regulated in cervical cancer, they did not validate these three miRNAs in terms of diagnostic value $[13,18,26,27]$. This study is the first to assess these miRNAs as putative biomarkers and their possible discriminatory capacity in FFPE tissues.

Differences in expression levels of the three miRNAs between HR-HPV E6/E7-positive cervical cancer tissue samples and HR-HPV E6/E7-negative cervical cancer tissue samples showed the strongest association was between miR-9 expression and HR-HPV E6/E7-positive cancer cases compared to that found with the other miRNAs (Fig. 2). Similarly, Weijun Liu et al. found miR-9 and HPV E6 caused increased cell motility by down regulating follistatin like 1 (FSTL1) and activated leukocyte cell adhesion molecule (ALCAM) mRNAs, both of which are involved in cell migration [28].

Both miR-21 and miR-155 had reported other mechanism related to immune response as well as HR-HPV E6/E7 expression. Bumrungthai et al. found that miR-21 is correlated with increased expression of $\alpha$-smooth muscle actin ( $\alpha$-SMA) and interleukin 6 (IL-6) and decreased expression of PDCD4 in cell proliferation and initiates inflammation-associated carcinogenesis via nuclear factor kappa-light chain-enhancer of activated $B$ cells (NF-kB) and interleukin-6 (IL-6) signaling pathways in colon and cervical cancer cells and Asangani et al. found miR-21 down-regulates PDCD4 in colon cancer and functions as stimulating invasion, intravasation, and metastasis [21, 22, 29]. For miR-155, Guoying Lao et al. found that miR-155 regulates LKB1 expression, which functions as embryonic polarity, metabolism, and cell growth and up-regulation of miR155 promotes proliferation of cervical cancer cells [23].

In terms of diagnostic value, miR-21, and miR-155 expression in combination with the HPV E6/E7 mRNA assay may be useful in the diagnosis of cervical cancer independent of HPV infection because these miR-21 and miR-155 may have the discriminatory power to detect HPV negative cervical cancer cases (Table 3). In 
particular, miR-21 was independent of HPV status being consistently up regulated in cervical cancer (Fig. 2). We analyzed the odds ratios to assess the effects of the predictors age, HPV E6/E7 mRNA expression, and expression of miR-9, miR-21, and miR-155 on cervical cancer compared to normal controls. While we found that all of the predictors were significantly associated with cervical cancer, miR-21 and miR-155 expression were identified as predictors for high risk in HPV negative cervical cancer tissues compared to normal cervical tissues (Tables 4 and 5).

Some studies have investigated miRNAs for association with HPV infection as potential diagnostic and prognostic indicators. Xiaohong Wang et al. revealed that miR-92a and miR-378 expression was associated with cancer progression in HPV positive tissue samples [30]. Similarly, we found that miR-155 overexpression is associated with increased risk of cervical cancer in HPV E6/E7 mRNA positive tissues. Moreover, miR-21 and miR-155 overexpression in HPV E6/E7 mRNA negative tissue samples could complement approaches for cervical cancer diagnosis and prediction of progression.

\section{Conclusions}

Our findings showed that miRNA RT-qPCR assays for specific miRs may be useful tools in the diagnosis of cervical cancer and especially, HPV negative cases of cervical cancer. In addition, these findings are important towards determining the possible role of miRNA expression in cervical cancer development, and the relationship between miRNA and HPV infection. Further study is needed in pre-cancer lesions to understand the role of miRNAs in tumor carcinogenesis, and more tests using normal and cervical cancer samples will be necessary to clearly demonstrate the potential utility of these assays for cervical cancer screening and diagnosis.

\begin{abstract}
Abbreviations
95\% Cl: 95\% confidential interval; ALCAM: Activated leukocyte cell adhesion molecule; AUC: Area under the ROC curve; FFPE: Formalin-fixed paraffinembedded; FSTL1: Follistatin like 1; GAPDH: Glyceraldehyde-3-phosphate dehydrogenase; HR-HPV: High risk human papillomavirus; IL-6: Interleukin-6; LKB1: Liver kinase B1; miRNA: microRNA; NPV: Negative predictive value; OR: Odds ratio; PPV: Positive predictive value; $\mathrm{pRb}$ : Retinoblastoma protein; ROC: Receiver operating characteristic; a-SMA: a-smooth muscle actin
\end{abstract}

\section{Funding}

This research was supported by Basic Science Research Program through the National Research Foundation of Korea (NRF) funded by the Ministry of Science, ICT and future Planning (2015R1A2A2A04004455).

\section{Availability of data and materials}

All relevant materials are described in the manuscript. Additional data sets supporting the conclusions of this article are available at request from the corresponding author.

\section{Authors' contributions}

$\mathrm{SP}, \mathrm{KE}$, and JK participated in the design of the study and performed the statistical analysis and manuscript. KE and $\mathrm{HJ}$ and $\mathrm{HW}$ carried out the data extraction. $\mathrm{HY}$ and KP and HB conceived of the study, and participated in its design and coordination and helped to draft the manscripts. GK, DL, and SK helped to assemble the clinical data and performed the initial data interpretation together with $\mathrm{HB}$ and organize the experiment and sample collection. All authors read and approved the final manuscript.

\section{Ethics approval and consent to participate}

Institutional Ethics Committee at Yonsei University Wonju College of Medicine approved the study protocol (approval no. YWMR-12-4-010) and all subjects provided written informed consent.

\section{Consent for publication}

Not applicable.

\section{Competing interests}

The authors declare that they have no competing interests.

\section{Publisher's Note}

Springer Nature remains neutral with regard to jurisdictional claims in published maps and institutional affiliations.

\section{Author details}

${ }^{1}$ Department of Biomedical Laboratory Science, College of Health Sciences, Yonsei University, Wonju-si, Gangwon-do 26493, Republic of Korea. ${ }^{2}$ Optipharm M\&D, Inc., Wonju Eco Environmental Technology Center, Wonju-si, Gangwon-do 26493, Republic of Korea. ${ }^{3}$ Department of Clinical Laboratory Science, College of Health Sciences, Catholic University of Pusan, Pusan, Republic of Korea. ${ }^{4}$ Department of Clinical Laboratory Science, Hyejeon College, Hongseoung, Republic of Korea. ${ }^{5}$ Department of Pathology, Wonju College of Medicine, Yonsei University Wonju College of Medicine, 20 Ilsan-ro, Wonju-si, Gangwon-do 26426, Republic of Korea.

Received: 27 August 2016 Accepted: 5 September 2017

Published online: 21 September 2017

\section{References}

1. McGuire S. World Cancer Report 2014. Geneva, Switzerland: World Health Organization, International Agency for Research on Cancer, WHO Press. 2015. Adv Nutr. 2016;7:418-9.

2. Crosbie EJ, Kitchener HC. Human papillomavirus in cervical screening and vaccination. Clin Sci (Lond). 2006;110:543-52.

3. Munger K, Werness BA, Dyson N, Phelps WC, Harlow E, Howley PM. Complex formation of human papillomavirus E7 proteins with the retinoblastoma tumor suppressor gene product. EMBO J. 1989;8:4099-105.

4. Koivusalo R, Mialon A, Pitkanen H, Westermarck J, Hietanen S. Activation of p53 in cervical cancer cells by human papillomavirus E6 RNA interference is transient, but can be sustained by inhibiting endogenous nuclear exportdependent p53 antagonists. Cancer Res. 2006;66:11817-24.

5. Liu X, Clements A, Zhao K, Marmorstein R. Structure of the human Papillomavirus E7 oncoprotein and its mechanism for inactivation of the retinoblastoma tumor suppressor. J Biol Chem. 2006:281:578-86.

6. Moody CA, Laimins LA. Human papillomavirus oncoproteins: pathways to transformation. Nat Rev Cancer. 2010;10:550-60.

7. Giorgi Rossi P, Sideri M, Carozzi FM, Vocaturo A, Buonaguro FM, Tornesello $M L$, Burroni E, Mariani L, Boveri S, Zaffina LM, et al. HPV type distribution in invasive cervical cancers in Italy: pooled analysis of three large studies. Infect Agent Cancer. 2012;7:26.

8. Tjalma WA, Fiander A, Reich O, Powell N, Nowakowski AM, Kirschner B, Koiss $R$, O'Leary J, Joura EA, Rosenlund $M$, et al. Differences in human papillomavirus type distribution in high-grade cervical intraepithelial neoplasia and invasive cervical cancer in Europe. Int J Cancer. 2013;132:854-67.

9. de Sanjose S, Quint WG, Alemany L, Geraets DT, Klaustermeier JE, Lloveras B, Tous S, Felix A, Bravo LE, Shin HR, et al. Human papillomavirus genotype attribution in invasive cervical cancer: a retrospective cross-sectional worldwide study. Lancet Oncol. 2010;11:1048-56.

10. Wang HY, Kim G, Cho H, Kim S, Lee D, Park S, Park KH, Lee H. Diagnostic performance of HPV E6/E7, hTERT, and Ki67 mRNA RT-qPCR assays on formalin-fixed paraffin-embedded cervical tissue specimens from women with cervical cancer. Exp Mol Pathol. 2015;98:510-6.

11. Bartel DP. MicroRNAs: genomics, biogenesis, mechanism, and function. Cell. 2004;116:281-97. 
12. Esquela-Kerscher A, Slack FJ. Oncomirs - microRNAs with a role in cancer. Nat Rev Cancer. 2006;6:259-69.

13. Guo J, Miao Y, Xiao B, Huan R, Jiang Z, Meng D, Wang Y. Differential expression of microRNA species in human gastric cancer versus nontumorous tissues. J Gastroenterol Hepatol. 2009;24:652-7.

14. Iorio MV, Ferracin M, Liu CG, Veronese A, Spizzo R, Sabbioni S, Magri E, Pedriali M, Fabbri M, Campiglio M, et al. MicroRNA gene expression deregulation in human breast cancer. Cancer Res. 2005;65:7065-70.

15. Takamizawa J, Konishi H, Yanagisawa K, Tomida S, Osada H, Endoh H, Harano T, Yatabe Y, Nagino M, Nimura Y, et al. Reduced expression of the let-7 microRNAs in human lung cancers in association with shortened postoperative survival. Cancer Res. 2004;64:3753-6.

16. Michael MZ, O'Connor SM, van Holst Pellekaan NG, Young GP, James RJ. Reduced accumulation of specific microRNAs in colorectal neoplasia. Mol Cancer Res. 2003:1:882-91.

17. Lui WO, Pourmand N, Patterson BK, Fire A. Patterns of known and novel small RNAs in human cervical cancer. Cancer Res. 2007;67:6031-43.

18. Lee JW, Choi CH, Choi JJ, Park YA, Kim SJ, Hwang SY, Kim WY, Kim TJ, Lee JH, Kim BG, Bae DS. Altered MicroRNA expression in cervical carcinomas. Clin Cancer Res. 2008;14:2535-42.

19. Gocze K, Gombos K, Juhasz K, Kovacs K, Kajtar B, Benczik M, Gocze P, Patczai B, Arany I, Ember I. Unique microRNA expression profiles in cervical cancer. Anticancer Res. 2013;33:2561-7.

20. Ma L, Young J, Prabhala H, Pan E, Mestdagh P, Muth D, Teruya-Feldstein J, Reinhardt F, Onder TT, Valastyan S, et al. miR-9, a MYC/MYCN-activated microRNA, regulates E-cadherin and cancer metastasis. Nat Cell Biol. 2010; 12:247-56.

21. Bumrungthai S, Ekalaksananan T, Evans MF, Chopjitt P, Tangsiriwatthana T, Patarapadungkit N, Kleebkaow P, Luanratanakorn S, Kongyingyoes B, Worawichawong S, Pientong C. Up-regulation of miR-21 is associated with cervicitis and human papillomavirus infection in cervical tissues. PLoS One. 2015;10:5.

22. Asangani I, Rasheed S, Nikolova D, Leupold J, Colburn N, Post S, Allgayer H. MicroRNA-21 (miR-21) post-transcriptionally downregulates tumor suppressor Pdcd4 and stimulates invasion, intravasation and metastasis in colorectal cancer. Oncogene. 2008;27:2128-36.

23. Lao G, Liu P, Wu Q, Zhang W, Liu Y, Yang L, Ma C. Mir-155 promotes cervical cancer cell proliferation through suppression of its target gene LKB1. Tumour Biol. 2014:35:11933-8.

24. Turner M, Vigorito E. Regulation of B- and T-cell differentiation by a single microRNA. Biochem Soc Trans. 2008:36:531-3.

25. Schiffman M, Castle PE, Jeronimo J, Rodriguez AC, Wacholder S. Human papillomavirus and cervical cancer. Lancet. 2007;370:890-907.

26. Wang X, Tang S, Le SY, Lu R, Rader JS, Meyers C, Zheng ZM. Aberrant expression of oncogenic and tumor-suppressive microRNAs in cervical cancer is required for cancer cell growth. PLoS One. 2008:3:e2557.

27. Pereira PM, Marques JP, Soares AR, Carreto L, Santos MA. MicroRNA expression variability in human cervical tissues. PLoS One. 2010;5:e11780

28. Liu W, Gao G, Hu X, Wang Y, Schwarz JK, Chen JJ, Grigsby PW, Wang X. Activation of miR-9 by human papillomavirus in cervical cancer. Oncotarget. 2014;5:11620-30

29. Deftereos G, Corrie SR, Feng Q, Morihara J, Stern J, Hawes SE, Kiviat NB. Expression of mir-21 and mir-143 in cervical specimens ranging from histologically normal through to invasive cervical cancer. PLoS One. 2011;6:e28423

30. Wang X, Wang HK, Li Y, Hafner M, Banerjee NS, Tang S, Briskin D, Meyers C, Chow LT, Xie X, et al. microRNAs are biomarkers of oncogenic human papillomavirus infections. Proc Natl Acad Sci U S A. 2014;111:4262-7.

\section{Submit your next manuscript to BioMed Central and we will help you at every step:}

- We accept pre-submission inquiries

- Our selector tool helps you to find the most relevant journal

- We provide round the clock customer support

- Convenient online submission

- Thorough peer review

- Inclusion in PubMed and all major indexing services

- Maximum visibility for your research

Submit your manuscript at www.biomedcentral.com/submit

) Biomed Central 